\title{
Effectiveness of physical therapy in postural neck pain with and without home based management.
}

\author{
Amir Bux Sial ${ }^{1,}$ Vinot kumar ${ }^{2,}$ Dr. Ramesh lal $^{3,}$ Reeta $^{4,}$ Umesh kumar ${ }^{5,}$ Iram \\ iqbal shamsi ${ }^{6,}$ Dr. Jetindar Puri ${ }^{7}$, Kailash Kumar $^{8}$ \\ ${ }^{1}$ senior Physiotherapist at institute of Orthpaedic and Surgery (Pvt) Karachi. \\ ${ }^{4,5,6}$ senior lecturer at IPMR Dow University health and sciences Karachi \\ ${ }^{2}$ Senior Physiotherapist at National Institute of Rehabilitation Medicine \\ ${ }^{3}$ Senior lecturer Faculty of dentistry LUMHS Jamshoro \\ ${ }^{7,8}$ Physiotherapist at jinnah postgraduate medical center Karachi
}

\begin{abstract}
Objective of the study: Postural neck pain is one of the most prevailing problems amongst patients. The purpose of this study was to determine the effectiveness of physical therapy in postural neck pain with home based exercises

Materials \& Methods: This study was a non randomized control trial conducted on 36 Patients having postural neck pain, recruited from physiotherapy department, National Institute of Rehabilitation Medicine Islamabad. Patients were assigned to either control group or intervention group. The intervention group received physiotherapy treatment and home-based exercises for neck pain relief, whereas the control group received only physiotherapy treatment. Six sessions of physiotherapy were performed on alternate days in both groups. The main outcome measure was Neck Disability Index (NDI), which was assessed at the start of study and then weekly for 2 weeks in both groups.

Results: There were 15 males and 25 females who were assigned to control and intervention group. Majority of patients in the intervention $(n=20)$ and control $(n=20)$ groups were of age 41-50 yrs. After 2 weeks, neck pain was assessed in the both groups. There was significant difference between both group ( $p$ value $=0.025$ ).

Conclusion: It is concluded that Home based exercises for neck relief has significant effect for reduction of neck pain in patients with postural neck pain
\end{abstract}

Keywords: Home based Exercise, Postural neck pain, NDI

\section{1-Pain}

\section{Introduction}

It can be defined as an unpleasant sensation and emotional experience that clearly affects quality of life and health. ${ }^{(1)}$

Pain can be acute, sub acute and chronic defined on the basis of time frame. Chronic pain usually persists for 36 months. ${ }^{(2)}$

\section{Statistics of neck pain}

According to statistics for neck pain in the general population, with 11-18\% incidence of 1 year. Pain can be mild, moderate or severe ${ }^{(3)} 33 \%$ of patients have chronic pain with serious health concerns according to a study; over $50 \%$ of patients with neck pain are referred for physical therapy and comprise approximately $25 \%$ of all patients seeking physical therapy services. ${ }^{(6)}$ In Pakistan many physical therapists advise self-management including ice and heat, rest, stretching, postural correction, massage as a part of treatment of neck pain. So aim of my study is to find the effectiveness of home based management education in postural neck pain patients. This study may help us in formulating the guidelines for the management of neck pain particularly postural neck pain which will benefit the patients with neck pain in particular and community as a whole in general.

\section{1-Neck Pain}

Neck pain is discomfort in any of the structures in the neck. These include muscles and nerves as well as spinal vertebrae and the cushioning disks in between. ${ }^{(8)}$ Neck pain (cervicalgia) is a common problem with two-thirds of the population having neck pain at some point in their lives. ${ }^{(9)}$ 
Effectiveness of physical therapy in postural neck pain with and without home based management.

\section{Neck (The Cervical Spine)}

Neck is part of a long flexible column, known as the spinal column or backbone, which extends through most of the body. ${ }^{(10)}$ It is composed of vertebrae that begin in the upper torso and end at the base of the skull $^{(\mathbf{1 1 1})}$ he neck supports the weight of the head and protects the nerves that carry sensory and motor information from the brain down to the rest of the body. In addition, the neck is highly flexible and allows the head to turn and flex in all directions. ${ }^{(12)}$

\section{Anatomy of the human neck \\ Bony anatomy}

The cervical spine (neck region) consists of seven bones (C1-C7 vertebrae). It is divided into 2 parts: upper and lower.

1) The upper cervical spine consists of the atlas (C1) and the axis (C2).These first 2 vertebrae are quite different from the rest of the cervical spine. The atlas articulates superiorly with the occiput (the atlantooccipital joint) and inferiorly with the axis (the atlantoaxial joint).

2) The 5 cervical vertebrae that make up the lower cervical spine, $\mathrm{C} 3-\mathrm{C} 7$, are similar to each other but very different from $\mathrm{C} 1$ and $\mathrm{C} 2$. Each has a vertebral body that is concave on its superior surface and convex on its inferior surface ${ }^{\cdot(13)}$

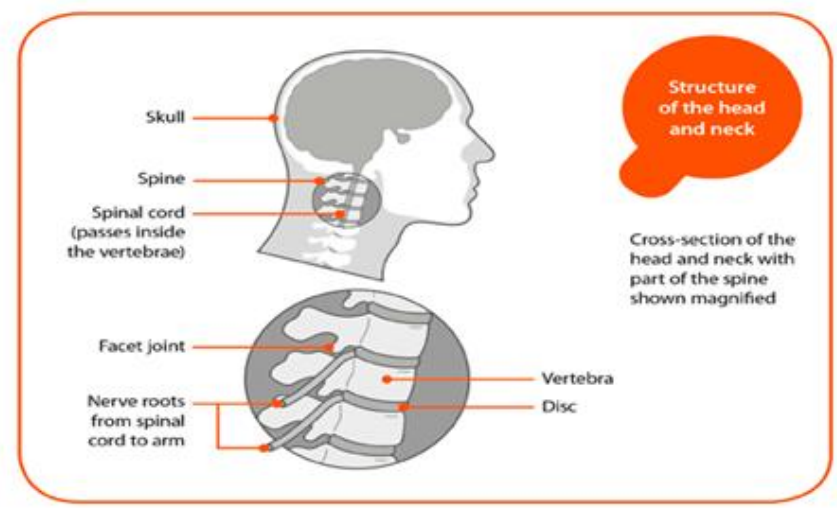

The cervical vertebrae are separated from one another by intervertebral discs. These discs act as shock absorbers and provide freedom of movement during activity. Attached to the back of each vertebral body is an arch of bone that forms a continuous hollow longitudinal space, which runs the whole length of your back. This space, called the spinal canal, is the area through which the spinal cord and nerve bundles pass. The spinal cord is bathed in cerebrospinal fluid (CSF) and surrounded by three protective layers called the meninges (dura, arachnoid, and pia mater). Two foramina are located laterally at each vertebral level, through which pairs of nerves pass. These nerves serve the muscles, skin and tissues of the body and thus provide sensation and movement to all parts of the body. The delicate spinal cord and nerves are further supported by strong muscles and ligaments that are attached to the vertebrae ${ }^{(10)}$

\section{Soft tissue anatomy}

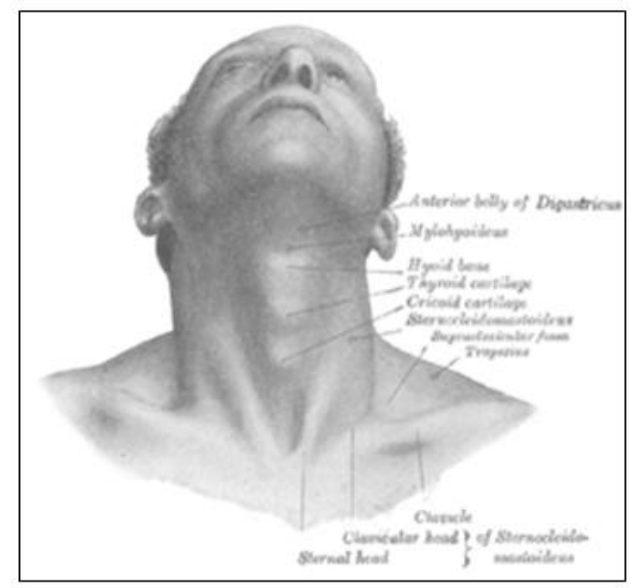


In the middle line below the chin can be felt the body of the hyoid bone, just below which is the prominence of the thyroid cartilage called "Adam's apple", better marked in men than in women. Still lower the cricoid cartilage is easily felt, while between this and the suprasternal notch the trachea and isthmus of the thyroid gland may be made out. At the side the outline of the sternomastoid muscle is the most striking mark; it divides the anterior triangle of the neck from the posterior. The upper part of the former contains the submaxillary gland also known as the sub-mandibular glands, which lies just below the posterior half of the body of the jaw. The line of the common and the external carotid arteries may be marked by joining the sterno-clavicular articulation to the angle of the jaw.

The eleventh or spinal accessory nerve corresponds to a line drawn from a point midway between the angle of the jaw and the mastoid process to the middle of the posterior border of the sterno-mastoid muscle and thence across the posterior triangle to the deep surface of the trapezius. The external jugular vein can usually be seen through the skin; it runs in a line drawn from the angle of the jaw to the middle of the clavicle, and close to it are some small lymphatic glands. The anterior jugular vein is smaller, and runs down about half an inch from the middle line of the neck. The clavicle or collar-bone forms the lower limit of the neck, and laterally the outward slope of the neck to the shoulder is caused by the trapezius muscle ${ }^{(1)}$

\section{Major muscles of neck Sternocleidomastoid}

Sternocleidomastoid muscle also known as sternomastoid and commonly abbreviated muscle as SCM, is a paired muscle in the superficial layers of the anterior portion of the neck; it is one of the largest and most superficial cervical muscles.Origin and insertion The Sternocleidomastoid passes obliquely across the side of the neck. It is thick and narrow at its central part, but broader and thinner at either end.The medial or sternal head is a rounded fasciculus, tendinous in front, fleshy behind, which arises from the upper part of the anterior surface of the manubrium sterni, and is directed superiorly, laterally, and posteriorly. The lateral or clavicular head, composed of fleshy and aponeurotic fibers, arises from the superior border and anterior surface of the medial third of the clavicle; it is directed almost vertically upward.The two heads are separated from one another at their origins by a triangular interval (supraclavicular fossa) but gradually blend, below the middle of the neck, into a thick, rounded muscle which is inserted, by a strong tendon, into the lateral surface of themastoid process, from its apex to its superior border, and by a thin aponeurosis into the lateral half of the superior nuchal line of the occipital.ActionThe function of this muscle is to rotate the head to the opposite side or obliquely rotate the head. It also flexes the neck. When acting together it flexes the neck and extends the head. When acting alone it rotates to the opposite side (contra laterally) and slightly (laterally) flexes to the same side.It also acts as an accessory muscle of inspiration, along with the scalene muscles of the neck

\section{Trapezius}

The trapezius is a large superficial muscle that extends longitudinally from the occipital bone to the lower thoracic and laterally to the spine of the scapula (shoulder blade). Its functions are to move the scapulae and support the arm. The trapezius has three functional regions: the superior region (descending part), which supports the weight of the arm; the intermediate region (transverse part), which retracts the scapulae; and the inferior region (ascending part), which medially rotates and depresses the scapulae. ActionContraction of the trapezius muscle can have two effects: movement of the scapulae when the spinal origins are stable and movement of the spine when the scapulae are stable. Its main function is to stabilize and move the scapula.

Scapular movements The upper and lower fibers tend to rotate the scapula around the sternoclavicular articulation so that the acromion and inferior angles move up and the medial border moves down. This rotation is in the opposite direction to that produced by levator scapulae and the rhomboids. The upper fibers do not contribute significantly to scapular elevation. The middle fibers retract the scapula.Spinal movements When the scapulae are stable a co-contraction of both sides can extend the neck.

\section{Splenius capitis}

Splenius capitis is a broad, straplike muscle in the back of the neck. It pulls on the base of the skull from the vertebrae in the neck and upper thorax. It is involved in simple movements such as shaking the head. Origin and insertion It arises from the lower half of the nuchal ligament, from the spinous process of the seventh cervical vertebra, and from the spinous processes of the upper three or four thoracic vertebrae.The fibers of the muscle are directed upward and laterally and are inserted, under cover of the sternocleidomastoideus, into the mastoid process of the temporal bone, and into the rough surface on the occipital bone just below the lateral third of the superior nuchal line. The splenius capitis is deep to sternocleidomastoideus at the mastoid process, and to the trapezius for its lower portion. The splenius capitis muscle is innervated by the posterior ramus of spinal nerves $\mathrm{C} 3$ and C4.Function The splenius capitis muscle is 
a prime mover for head extension. The splenius capitis can also allow lateral flexion and rotation of the cervical spine.

\section{Splenius cervicis}

Splenius cervicis (also known as the splenius colli) is a muscle in the back of the neck. It arises by a narrow tendinous band from the spinous processes of the third to the sixth thoracic vertebrae; it is inserted, by tendinous fasciculi, into the posterior tubercles of the transverse processes of the upper two or three cervical vertebrae.The function of the splenius cervicis muscle is extension of the cervical spine, rotation to the ipsilateral side and lateral flexion to the ipsilateral side.

\section{Longus capitis muscle}

longus capitis muscle (rectus capitis anticus major), broad and thick above, narrow below, arises by four tendinous slips, from the anterior tubercles of the transverse processes of the third, fourth, fifth, and sixth cervical vertebræ, and ascends, converging toward its fellow of the opposite side, to be inserted into the inferior surface of the basilar part of the occipital bone. It is innervated by a branch of cervical plexus. Longus capitis has several actions, acting unilaterally to flex the head and neck laterally, rotate the head ipsilaterally, acting bilaterally flex the head and neck

\section{Longus colli muscle}

Longus colli muscle is a muscle of the body. The Longus colli is situated on the anterior surface of the vertebral column, between the atlas and the third thoracic vertebra. It is broad in the middle, narrow and pointed at either end, and consists of three portions, a superior oblique, an inferior oblique, and a vertical.

The superior oblique portion arises from the anterior tubercles of the transverse processes of the third, fourth, and fifth cervical vertebræ and, ascending obliquely with a medial inclination, is inserted by a narrow tendon into the tubercle on the anterior arch of the atlas. The inferior oblique portion, the smallest part of the muscle, arises from the front of the bodies of the first two or three thoracic vertebræ; and, ascending obliquely in a lateral direction, is inserted into the anterior tubercles of the transverse processes of the fifth and sixth cervical vertebræ.The vertical portion arises, below, from the front of the bodies of the upper three thoracic and lower three cervical vertebræ, and is inserted into the front of the bodies of the second, third, and fourth cervical vertebræ.

\section{Longus capitis muscle}

longus capitis muscle (rectus capitis anticus major), broad and thick above, narrow below, arises by four tendinous slips, from the anterior tubercles of the transverse processes of the third, fourth, fifth, and sixth cervical vertebræ, and ascends, converging toward its fellow of the opposite side, to be inserted into the inferior surface of the basilar part of the occipital bone.

\section{Semispinalis capitis}

Semispinalis capitis is situated at the upper and back part of the neck, deep to the splenius, and medial to the longissimus cervicis and capitis. It is part of the transversospinales muscle group.It arises by a series of tendons from the tips of the transverse processes of the upper six or seven thoracic and the seventh cervical vertebrae, and from the articular processes of the three cervical vertebrae above this (C4-C6). The tendons, uniting, form a broad muscle, which passes upward, and is inserted between the superior and inferior nuchal lines of the occipital bone. It lies deep to the trapezius muscle and can be palpated as firm round muscle mass just lateral to the cervical spinous processes. The semispinalis muscles are innervated by the dorsal rami of the cervical spinal nerves.

\section{Semispinalis cervicis}

Semispinalis cervicis (semispinalis colli), arises by a series of tendinous and fleshy fibers from the transverse processes of the upper five or six thoracic vertebrae, and is inserted into the cervical spinous processes, from the axis to the fifth inclusive. The fasciculus connected with the axis is the largest, and is chiefly muscular in structure. The semispinalis cervicis is thicker than the semispinalis dorsi.

\section{Rectus capitis anterior}

Rectus capitis anterior is a short, flat muscle, situated immediately behind the upper part of the Longus capitis.It arises from the anterior surface of the lateral mass of the atlas, and from the root of its transverse process, and passing obliquely upward and medial, is inserted into the inferior surface of the basilar part of the occipital bone immediately in front of the foramen magnum. Action: flexion of the head and the neck; Nerve supply: C1, C2. 


\section{Rectus capitis lateralis:}

Rectus capitis lateralis, a short, flat muscle, arises from the upper surface of the transverse process of the atlas, and is inserted into the under surface of the jugular process of the occipital bone

\section{Kinesiology of the Neck}

Flexion, extension, rotation, lateral flexion, and circumduction are the basic movements of the cervical region. [2]

\begin{tabular}{|l|ll|l|}
\hline Joint Motion & \multicolumn{2}{|l|}{ Prime Movers } & Accessories \\
\hline FLEXION & - & Sternocleidomastoid & Scalenes \\
& - & Longuscolli & Hyoid muscles \\
& - & Longuscapitis & \\
& - & Rectus capitis anterior & \\
\hline EXTENSION & - & Rectus capitislateralis & \\
& - & Trapezius, upper & Transversospinalis group \\
& - & Splenius capitis & Levator scapulae \\
& - & Splenius cervicis & \\
& - & Semispinaliscapitis & \\
& - & Semispinaliscervicis & \\
& - & Erector spinaecapitis & \\
\hline ROTATION & - & Erector spinaecervicis & \\
& - & Sternocleidomastoid & Scalenes \\
& - & Trapezius, upper & Transversospinalis group \\
& - & Speniuscapitis & \\
\hline LATERAL & - & Speniuscervicis & \\
\hline FLEXION & - & Scalenes & Transversospinalis group \\
& & Levator scapulae & Rectus capitis lateralis \\
\hline
\end{tabular}

\section{Normal Kinematics of the Cervical Column}

At the $\mathrm{C} 2$ through $\mathrm{C} 3$ junction, the upper cervical spine meets the remaining, more typical cervical column. The body of the axis acts as a "root" within $\mathrm{C} 3$, securing the upper cervical spine in the remaining cervical column. The articulating surfaces of the inferior and superior inter-vertebral joints are similar to a saddle joint, maintaining anterior-posterior and medially and laterally directed concavities. This orientation of the cervical bodies of the mid to lower cervical column allows for rotation and flexion movements but is resistant to lateral flexion. Lateral flexion is possible as a combined movement in the cervical column but only due to coupled rotational movement in each segment to that side.

General flexion and extension motion of the neck does not necessarily reflect the movement among vertebrae in the cervical spine. In fact, a vertebra may experience its greatest range of motion in flexion or extension before the cervical column itself has fully flexed or extended. Furthermore, a vertebra may experience a large range of movement in one direction while the cervical column on the whole exhibits movement in the opposite direction. The order of contribution from cervical segments into flexion and extension varies by level as well. Flexion is initiated at the lower cervical spine ( $\mathrm{C} 4$ through $\mathrm{C} 7$ ), followed by motion at $\mathrm{C} 0$ (occiput) through $\mathrm{C} 2, \mathrm{C} 2$ through $\mathrm{C} 3$, and then $\mathrm{C} 3$ through $\mathrm{C} 4$. The $\mathrm{C} 6$ through $\mathrm{C} 7$ segment undergoes a brief reversal of motion into extension, followed by a reversal of motion at $\mathrm{C} 0$ through $\mathrm{C} 2$. The C6 through $\mathrm{C} 7$ segment contributes to the end ranges of flexion. Extension is also initiated in the lower cervical spine $(\mathrm{C} 4$ through $\mathrm{C} 7)$ and is followed by the beginning of motion at $\mathrm{C} 0$ through $\mathrm{C} 2$. The middle range consists of varied movement from the mid cervical region, whereas the lower cervical spine is the last to contribute as the column moves into terminal extension.

\section{Grades of neck pain}


Effectiveness of physical therapy in postural neck pain with and without home based management.

\begin{tabular}{|l|l|}
\hline Description & Symptoms/signs \\
\hline $\begin{array}{l}\text { Grade I } \\
\text { No signs of major pathology and no or little interference }\end{array}$ & $\begin{array}{l}\text { stiffness, tenderness, but no significant neurological } \\
\text { complaints } \\
\text { no signs and symptoms of major structural pathology (e.g. } \\
\text { fracture, dislocation, infection, etc) }\end{array}$ \\
\hline $\begin{array}{l}\text { Grade II } \\
\text { No signs of major pathology, but interference with daily } \\
\text { activities }\end{array}$ & $\begin{array}{l}\text { neck pain interference with daily } \\
\text { activities } \\
\text { no signs and symptoms of major structural pathology or root } \\
\text { compression }\end{array}$ \\
\hline $\begin{array}{l}\text { Grade III } \\
\text { Neck pain with neurological signs or symptoms }\end{array}$ & $\begin{array}{l}\text { complaints of neck pain associated with significant } \\
\text { neurologic signs (e.g. decreased deep tendon reflexes, } \\
\text { weakness, sensory deficits) } \\
\text { these complaints suggest malfunction of spinal nerves or the } \\
\text { spinal cord }\end{array}$ \\
\hline $\begin{array}{l}\text { Grade IV } \\
\text { Neck pain with signs of major pathology }\end{array}$ & $\begin{array}{l}\text { complaints of neck pain and/or its associated disorders along } \\
\text { with symptoms of major structural pathology, detected by } \\
\text { clinician } \\
\text { be aware of red flags for fractures, myelopathy, infection, } \\
\text { neoplasm, other destructive lesions or systemic diseases }\end{array}$ \\
\hline
\end{tabular}

\section{Causes of neck pain}

Neck pain may result from abnormalities in the soft tissues - the muscles, ligaments, and nerves - as well as in bones and joints of the spine. The most common causes of neck pain are soft-tissue abnormalities due to injury or prolonged wear and tear. In rare instances, infection or tumors may cause neck pain. In some people, neck problems may be the source of pain in the upper back, shoulders, or arms. ${ }^{.(4)}$

\section{Inflammatory Diseases}

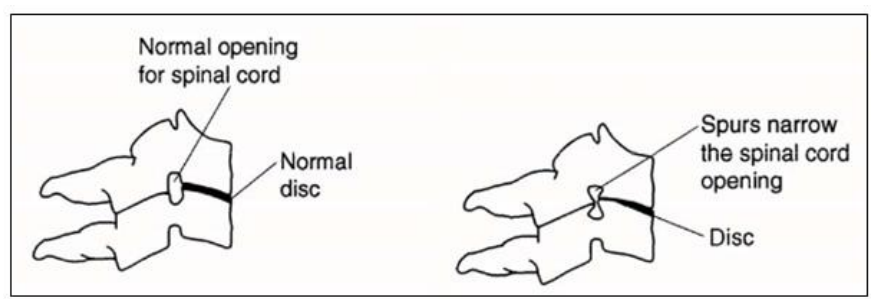

Rheumatoid arthritis can destroy joints in the neck and cause severe stiffness and pain. Rheumatoid arthritis typically occurs in the upper neck area.[4] Arthritis is when the bone surfaces become rough, which can cause irritation to the disc and nerve as well ${ }^{(5)}$

\section{Poor Posture}

Poor posture because an aching pain in muscles that tends to be associated with sitting at a computer or other job-related tasks. Postural mal-alignments resulting in poor biomechanics ${ }^{(7)}$ Patients can become sore in different parts of the body like the neck and arms, and often patients report they have difficulty sleeping or feeling restored from sleep. ${ }^{(6)}$

\section{Cervical Disk Degeneration (Spondylosis)}

The disk acts as a shock absorber between the bones in the neck. Spondylosis and impaired function of muscle, connective tissue and nervous tissue. ${ }^{(5)}$ In cervical disk degeneration (which typically occurs in people age 40 years and older), the normal gelatin-like center of the disk degenerates and the space between the vertebrae narrows. As the disk space narrows, added stress is applied to the joints of the spine causing further wear and degenerative disease. ${ }^{(4)}$

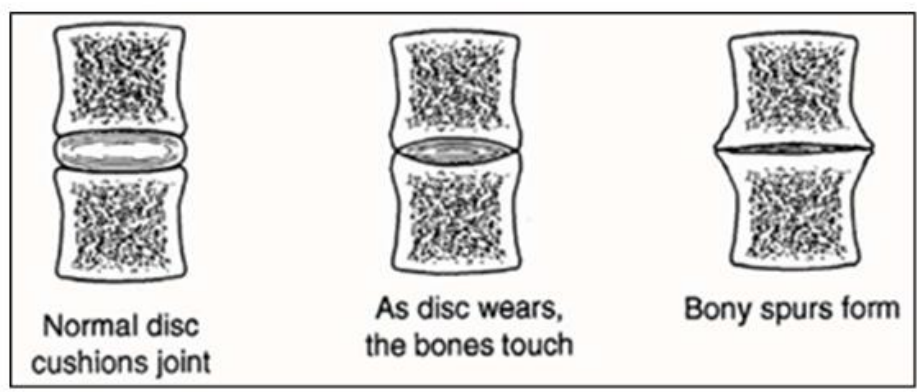




\section{Disk herniation}

A herniated disk refers to a problem with one of the rubbery cushions (disks) between the individual bones (vertebrae) that stack up to make your spine, that makes them less flexible and more prone to tearing or rupturing with even a minor strain or twist. A herniated disk can irritate nearby nerves and result in pain, numbness or weakness in an arm or leg. ${ }^{(7)}$

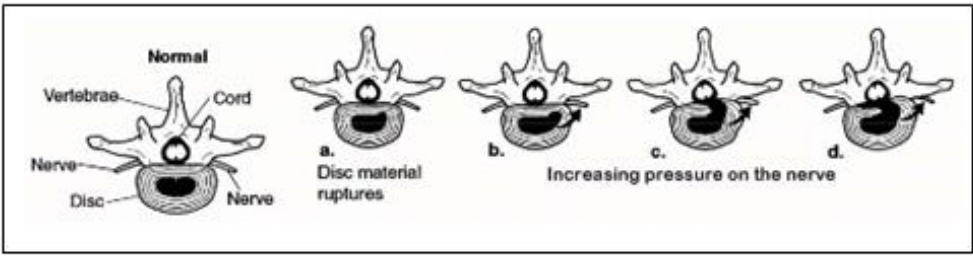

Injury

Because the neck is so flexible and because it supports the head, it is extremely vulnerable to injury. Motor vehicle or diving accidents, contact sports, and falls may result in neck injury. A "rear end" automobile collision may result in hyperextension, a backward motion of the neck beyond normal limits, or hyper flexion, a forward motion of the neck beyond normal limits. Severe neck injuries with a fracture or dislocation of the neck may damage the spinal cord and cause paralysis. ${ }^{(4)}$
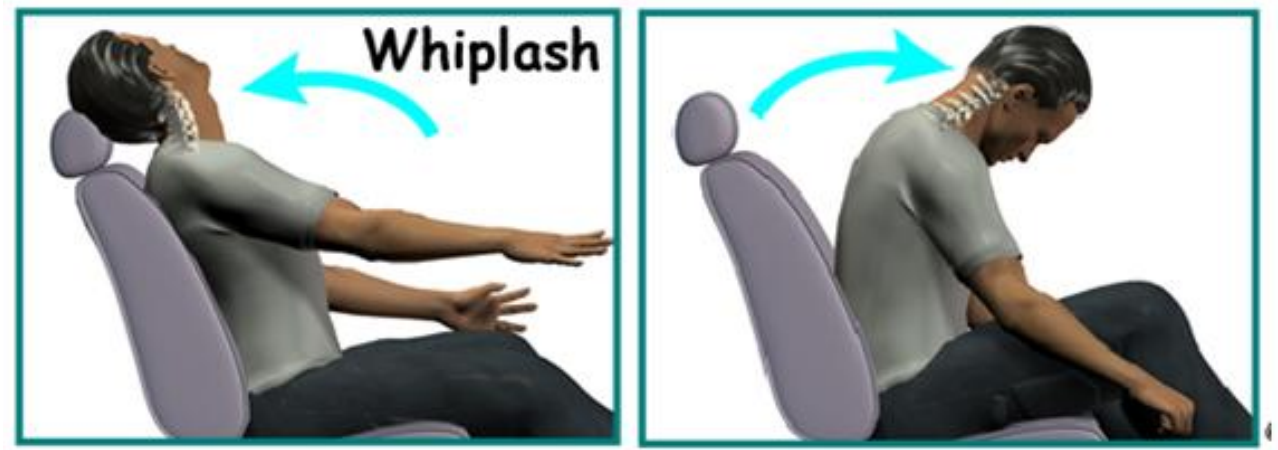

\section{Non-Spinal Causes of Neck Pain}

Non-spinal causes of neck pain are pain imitating a neck injury, but from another cause. Shoulder and elbow injuries and gall bladder disease are examples of problems that can refer pain to the neck area. ${ }^{(6)}$

\section{Repetitive Strain Injury}

Repetitive Strain Injury occurs from a chronically used part of the body, either in a normal or abnormal way. These problems are often found in people who sit at desks or work at computers. ${ }^{\text {(6) }}$ Workers such as lifting done by construction workers.

\section{Diseases}

Neck pain can sometimes be caused by diseases, such as rheumatoid arthritis, meningitis or cancer. ${ }^{(8)}$

\section{Acute (sudden onset) torticollis}

This is sometimes called 'wry neck'. A torticollis is when the head becomes twisted to one side and it is very painful to move the head back straight. The cause of acute primary torticollis is often not known. However, it may be due to a minor strain or sprain to a muscle or ligament in the neck. Some cases may be due to certain muscles of the neck being exposed to cold ${ }^{(9)}$

\section{Psychological neck pain}

Many of the patients experience neck pain as a result of some mental illness or stress as cervical muscles are most prone to get spasm.

\section{Typical Risk factors for Neck Pain Age}

The neck is often affected by the wear-and-tear variety of arthritis (osteoarthritis), which may come with age.

\section{Occupation}


Your risk of neck pain may be higher if your job requires your neck to be held in one position for prolonged periods of time. Especially if this position is not one of optimal posture where the curvatures of the spine are maintain. Examples include driving and computer work. There are some positions and or postures that are just bad for your neck and long careers in these postures may be hazardous.

\section{Bad Habits}

The most common aggravating and causing factors of neck pain are poor work and or leisure posture. The effects are cumulative, where for a long period of time there may be no signs and symptoms and what we call subclinical in nature.

\section{Genetics}

Some conditions that may lead to neck pain are genetic, osteoarthritis, RA, skeletal structural alignment, etc and having this tendency should make you even more diligent in your lifestyle to prevent progression $^{(10)}$

\section{How is Neck Pain Diagnosed?}

- X-rays: Plain X-rays can reveal narrowing of the space between two spinal bones, arthritis-like diseases, tumors, slipped discs, narrowing of the spinal canal, fractures and instability of the spinal column.

- MRI: Magnetic resonance imaging is a noninvasive procedure that can reveal the detail of neural (nerverelated) elements, as well as problems with the tendons and ligaments.

- Electrodiagnostic studies: Electromyography (EMG) and nerve conduction velocity (NCV) are sometimes used to diagnose neck and shoulder pain, arm pain, numbness and tingling.

- Myelography/CT scanning: Sometimes used as an alternative to MRI. ${ }^{(11)}$

\section{Symptoms of neck pain}

- General pain located in the neck area, as well as stiffness in the neck muscles. The pain may radiate down to the shoulder or between the shoulder blades.

- It may also radiate out into the arm, the hand or up into the head, causing a one-sided or double-sided headache.

- The muscles in the neck are tense, sore and feel hard to the touch.

- Acute pain can give rise to abnormal neck posture in which the head is forced to turn to one side. This condition is known as torticollis.

- The pain at the base of the skull may be accompanied by a feeling of weakness in the shoulders and arms.

- There may be a prickly or tingling sensation in the arms and fingers. ${ }^{(\mathbf{1 2})}$

\section{2- What is postural neck pain?}

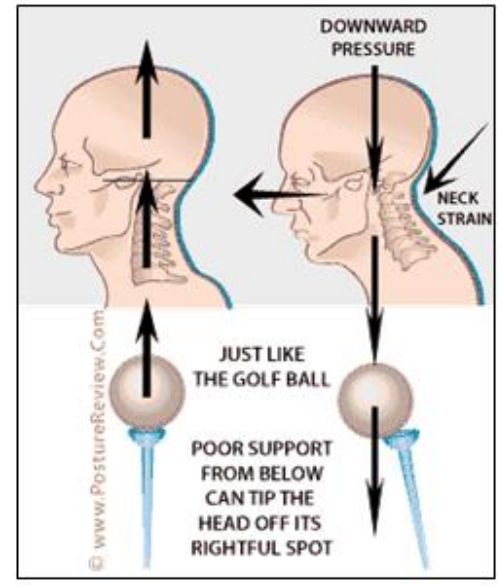

When the posture or integrity of the neck is compromised, it is easily susceptible to strain, tension, and fatigue. While this may not be an issue in the short term, long term exposure to poor head and neck posture can often lead to headaches, neck strain, and even degeneration of the bones, discs, and joints.

Often tension and pain found at the back of the neck can be associated with Forward Head Posture and an increase of the curving forward of the upper back (Thoracic Kyphosis), this is called as upper cross syndrome. "Abnormalities in head posture are often considered to be associated with the development and persistence of neck pain" 
As the head moves forward, the muscles of the front of the neck have the tendency of over stretching and lengthening while the muscles of the back of the neck, shoulder, and upper back tend to shorten excessively. This can create a neck pain cycle that may be difficult to resolve without the assistance of a qualified health care provider. ${ }^{(13)}$

\section{Facts about postural neck pain}

Research in the Journal SPINE, highlighted that "the sitting position has been identified as a risk factor for the development and increased frequency and severity of neck pain" (Horton et al, 2010) An article in the Journal MANUAL THERAPY goes on to say that the "prevalence of neck and shoulder girdle pain in office workers using computers may be as high as $31 \%$ ".

Szeto et al, 2002, describe the common characteristics that can be found in office workers include a combination of:

- Flexion or forward bending of the lower part of the neck;

- Tilting of the head upwards and forward;

- Rounding of the shoulders, with the shoulder hlades movina nutrulards towards the sides; ${ }^{(13)}$

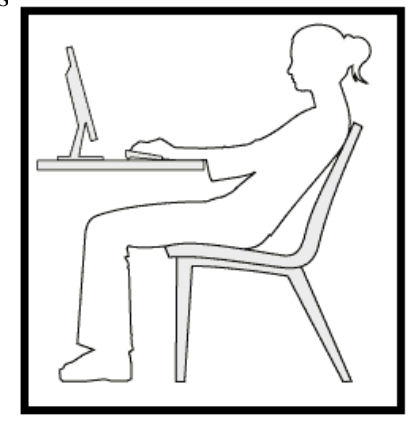

There is evidence that as we age (over 50 years of age) our head will tend to rest in a more forward position. While this may not always lead to pain in the neck, the prolonged forward head resting position may have increased probability of neck pain. ${ }^{(13)}$ Research conducted by the School of Rehabilitation Therapy, Queen's University, Canada, found that correcting forward head sitting posture lead to a direct easing of muscle activity at the neck. This will reduce strain on back muscles hence reduce the incidence of neck pain. ${ }^{(\mathbf{1 3})}$

\section{Postural Abuse and the Upper Cross Syndrome}

A good balanced posture is the key to a healthy spine, where the muscles that move the spine are constantly firing, contracting and relaxing to maintain stability, working in synergy with the larger muscles that move the arms and legs to make body movement more efficient and less taxing on joints. As children we have the potential to develop good postural habits such as sitting up straight and bending are knees to pick something up from the floor, but as we grow we develop bad postural habits from observing the adults around us. Hours in front of the TV, sitting at the computer, mountain bike riding, long distance driving or any job/activity that involves constantly leaning forward can put a tremendous amount of strain through our back, neck and shoulders. These prolonged static postures cause the body to adapt and as a result we start to develop muscle imbalances which then have an impact on the way are joints function leaving us more prone to injury.

Muscles need to be used regularly to make them strong but they also need to be stretched regularly to make them flexible. A healthy muscle is one that is well-toned but also relaxed! Unfortunately modern society puts demands on us meaning that more and more of us are travelling by car rather than walking and spending long hours sat at desks, neglecting the health of our muscles. If a muscle is not used very much it becomes weak and loses its elasticity, which makes movement more difficult. If a muscle becomes tight or over contracted, then it will stay tight even if you are not moving. This can lead to poor range of movement, stiffness and wear and tear on a joint. If a muscle becomes weak or overstretched it is not able to support the joint properly and sudden quick movements can lead to irritation of the joint and damage to its surrounding ligaments.

\section{Upper Cross Syndrome}

Upper Cross Syndrome is a very common uncomfortable and painful postural complaint that is seen in adults of all ages who adopt prolonged static postures. Secretarial or administrative staff, teachers, designers, bank clerks, taxi drivers, cyclists, hairdressers, gym junkies and Play station fanatics are to name just a few examples of the kind of individual that can be affected. 


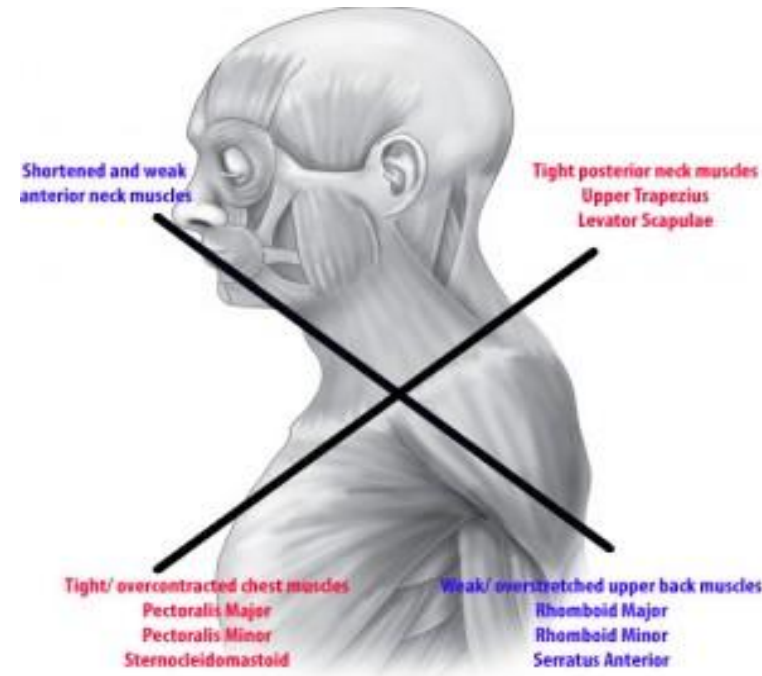

This static postural overuse causes the anterior neck and chest muscles to become tight and shortened, the muscles that attach to the shoulder blades become weak and stretched and the anterior neck muscles are held in a permanently shortened state. This all results in a posture where the head is held forward over the chest, the shoulders are rounded and a hunch develops through the upper back. With the spine and muscles now held in this position, strain is put through the joints of the neck and upper back and can cause symptoms such as headaches and pain in the neck, upper back and shoulders. It can also lead to a condition called thoracic outlet syndrome where the nerves that supply the arms and hands become irritated from shortened tight muscles in the neck and chest and can cause symptoms such as pins and needles, pain or weakness in the arms, hands or fingers.

People with upper cross syndrome may also find that they suffer from breathing problems due to the rib cage not being able to fully expand for lung inflation. As well as the lungs being compromised, there is less cavity space for the stomach and intestines and this can lead onto IBS type symptoms such as constipation, diahorrea, abdominal pain and bloating or regular bouts of indigestion. ${ }^{(32)}$

\section{Cervical postural syndrome}

This condition is characterized by a protruding chin and rounded shoulders. A common complaint is that of burning or aching across the neck and shoulders. Pain is aggravated by maintaining one position for long periods. Office workers who work at a computer are most likely to suffer from this condition.

Cervical postural syndrome is sometimes also called upper cross syndrome. This is due to the muscle imbalances which are present with this type of posture ${ }^{(33)}$

\section{Posture correction during different activities of daily life}

Following Posture correction techniques should be used during different activities of daily life

\section{Sitting}

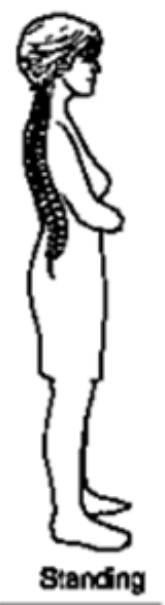

Chin tuck in along with back supported chair is suggested for sitting position 


\section{Standing}

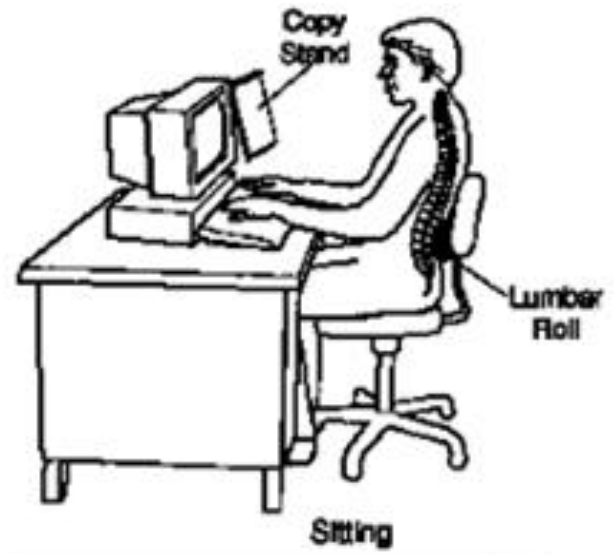

Spine must be kept in neutral position, neck in straight position with shoulders relaxed

Sleeping

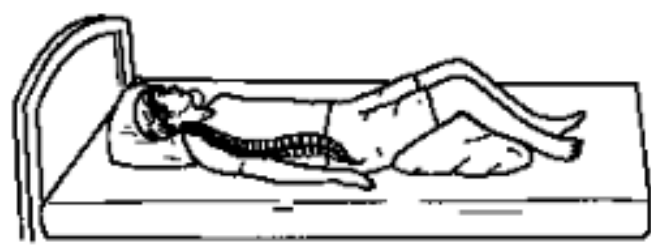

Keep your neck in a midline position. Avoid prone lying. Use pillows to relax your arms as well as legs

\section{Working}

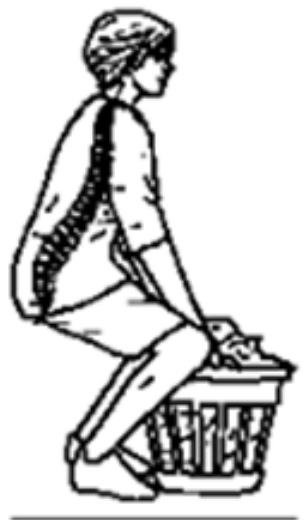

Take frequent breaks and change your position during activities

Driving

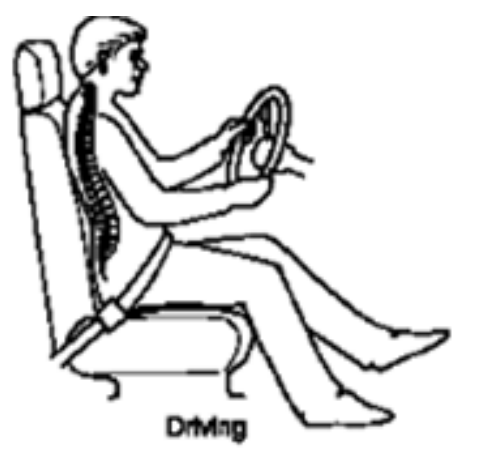

Sit with the seat upright and close enough to the wheel and controls that you do not need to reach forward. Adjust your headrest to the height of your head. 
Effectiveness of physical therapy in postural neck pain with and without home based management.

Lifting and Bending

Bend your knees to lift, not your back. Keep the load close to you and avoid reaching for any length of time. Avoid jerky movements. [5]

\section{3-Interventions For Neck Pain}

\section{Exercise your neck and keep active}

Aim to keep your neck moving as normally as possible. At first the pain may be quite bad, and you may need to rest for a day or so. However, gently exercise the neck as soon as you are able. You should not let it 'stiffen up'. Gradually try to increase the range of the neck movements. Every few hours gently move the neck in each direction. Do this several times a day. As far as possible, continue with normal activities. You will not cause damage to your neck by moving it.

\section{Medicines}

Painkillers are often helpful.

- Paracetamol at full strength is often sufficient. For an adult this is two $500 \mathrm{mg}$ tablets, four times a day.

- Anti-inflammatory painkillers. Some people find that these work better than paracetamol. They can be used alone or combined with paracetamol. They include ibuprofen which you can buy at pharmacies or get on prescription. Other types such as diclofenac or naproxen need a prescription. Some people with stomach ulcers, asthma, high blood pressure, kidney failure, or heart failure may not be able to take antiinflammatory painkillers.

- A stronger painkiller such as codeine is an option if anti-inflammatories do not suit or do not work well. Codeine is often taken in addition to paracetamol. Constipation is a common side-effect from codeine. To prevent constipation, have lots to drink and eat foods with plenty of fiber.

- A muscle relaxant such as diazepam is occasionally prescribed for a few days if your neck muscles become very tense and make the pain worse.

\section{Other treatments}

Some other treatments which may be advised include:

A good posture may help. Check that your sitting position at work or at the computer is not poor. (That is, not with your head flexed forward with a stooped back.) Sit upright. Yoga, Pilates, and the Alexander technique all improve neck posture, but their value in treating neck pain is uncertain.

A firm supporting pillow seems to help some people when sleeping. Try not to use more than one pillow.

Physiotherapy: The rehabilitation of neck injuries occurs in three phases.

1. During the first phase, called the acute phase, physiatrists treat pain and inflammation. After they make a specific diagnosis and develop a treatment plan, physiatrists may offer treatment options like ultrasound, electrical stimulation, mobilization, medication, ice and even specialized injections.

2. In the second, or recovery, phase of treatment, flexibility and strength are developed to get the body parts into their proper positions. The goal of this phase is to get you back to your usual work, sports and leisure activities. This goal is achieved through specially designed exercises that rebuild the body.

3. The main goal of the third phase of treatment, the maintenance phase, is to minimize recurrence of the problem and to prevent further injury. This often consists of a total body fitness program, designed to maintain body mechanics and increase endurance after the original symptoms have resolved. ${ }^{(\mathbf{8})}$

Injections: In some cases, especially where pain travels to the back of your head or arm, an injection of long-acting local anesthetic and/or steroid may help. It may be given into the small facet joints of your neck or sometimes into the narrow spaces where the nerves emerge from your spine. These injections are usually performed in an X-ray department so that the specialist can position the needle precisely.

Collars: Some people find a special collar helpful if a pinched nerve is causing pain that travels down their arm. It's best not to wear them for long periods. There's no evidence that they help with the causes of either short- or long-term neck pain.

Surgery: is only rarely needed. It may be helpful if a nerve or your spinal cord is being squeezed and causing weakness or severe pain that won't go away. The surgeon will take a scan of your nerves and bones before discussing the pros and cons of surgery with you. ${ }^{(14)}$

\section{Prevention}

The following steps can prevent neck pain or help your neck pain improve:

- Use relaxation techniques and regular exercise to prevent unwanted stress and tension to the neck muscles.

- Learn stretching exercises for your neck and upper body. Stretch every day, especially before and after exercise. A physical therapist can help. 
- Use good posture, especially if you sit at a desk all day. Keep your back supported. Adjust your computer monitor to eye level. This prevents you from continually looking up or down.

- If you work at a computer, stretch your neck every hour or so.

- Use a headset when on the telephone, especially if answering or using the phone is a main part of your job.

- When reading or typing from documents at your desk, place them in a holder at eye level.

- Evaluate your sleeping conditions. Make sure your pillow is properly and comfortably supporting your head and neck. You may need a special neck pillow. Make sure your mattress is firm enough.

- Use seat belts and bike helmets to prevent injuries. ${ }^{(15)}$

- Avoid the following exercises during your initial recovery, unless your doctor or physical therapist says it is okay:

$>$ Jogging

$>$ Football

$>$ Golf

$>$ Weight lifting

$>$ Leg lifts when lying on your stomach

$>$ Sit-ups with straight legs (rather than bent knee)

\section{4- Home management for neck pain}

1. Alternate heat and cold.

Reduce inflammation by applying cold, such as an ice pack or ice wrapped in a towel, for up to 20 minutes several times a day. Or alternate the cold treatment with heat. Try taking a warm shower or using a heating pad on the low setting. Heat can help relax sore muscles, but it sometimes aggravates inflammation, so use it with caution. ${ }^{(16)}$

\section{Rest.}

Lie down from time to time during the day to give your neck a rest from holding up your head. Avoid prolonged rest, since too much inactivity can cause increased stiffness in your neck muscles. ${ }^{\text {(16) }}$

\section{Get Out of Your Slump}

Bad posture is a major contributor to neck pain. Think about your posture every time you are sitting, standing, or lifting. Always try to keep your head and neck straight and make sure your back is supported. When you sit at your desk, for example, your computer should be at eye level and your chair should be right up against your back (in other words, don't press your nose against the computer screen). When you go to pick something up, don't lean forward. Instead, bend from your knees and keep your back straight. ${ }^{(17)}$

\section{Massage}

Gently massage or rub the area to relieve pain and encourage blood flow. Don't massage the injured area if it causes pain. Nonprescription creams or gels may provide pain relief. ${ }^{(18)}$

\section{Gentle stretching.}

Once you are feeling well enough and your doctor gives permission, practice stretching exercises to both relieve neck pain and improve your flexibility. It's best to perform these exercises after warming up muscles with a warm shower, bath, or towel. Here are a few simple stretches for cervical disc disease that can be advised at home:

1. Slowly turn your head to the left. With your left hand, apply very light tension on your chin so that your head turns slightly more. Hold for 20 seconds and return your head slowly to center. Repeat on the right side. This would stretch the rotators.

2. Tilt your head to the left and try to touch your left ear to your shoulder. With your left hand, apply light pressure on your temple. Hold for 20 seconds and repeat on the right side.

3. Bend your head forward and try to touch your chin to your chest. Relax the shoulders as you do this. Hold for 20 seconds and repeat. This would stretch neck extensors

4. Lie on your back with your knees bent and a pillow under your head and neck for support. Nod your head forward gently, as though you were saying "yes." Hold the position for 10 seconds and then relax. Repeat 10 times. If you feel significant discomfort with any of these stretches, stop immediately.(17)

\section{5- Prognosis of neck pain}

Most patients with mild to moderate cases of neck injury heal quickly and have a full recovery with appropriate physiotherapy treatment. In these instances, recovery may take a few days in the case of a single joint sprain for example, a "kink in the neck" some take weeks and months to resolve if the nature of the injury is repetitive strain. In severe and chronic cases, recovery may be significantly longer. Patients with chronic neck 
Effectiveness of physical therapy in postural neck pain with and without home based management.

pain may also have an increased likelihood of developing degenerative changes to their joints resulting in long term problems with restricted movement and pain. Immediate treatment for patients with neck is essential to ensure a speedy recovery, and chronic neck pain can be treated well with a strategic treatment plan. The success rate of treatment in patients varies and is largely dictated by patient compliance.

\section{6- Rationale of the study}

In Pakistani settings most of the patients do not follow or do not give importance to the home based intervention programs. Furthermore most of the people have assumed only medicines are the best solution for their ailments so they don't rely on physical treatments that probably require more time as well as more efforts at patients end. Therefore, patient must get awareness about the significance of physical therapy treatment and self management especially in prevention and cure for a particular problem.

Various studies suggest that home based self management has a major role in treating posture associated pains. Here it is hypothesized that postural neck pains can be treated with long term exercises that include stretching exercises, positional release, isometric and iso-kinetic strengthening exercises and postural correction exercises. In Asian community people are more prone to postural issues due to lack of awareness, further they have weaker bones due to decreased bone minerals especially decreased Vitamin D levels so they are more prone to neck and back pains. This study involves correction of posture associated neck pain in Pakistani community with the help of home based exercise instructions continued in the long run for the benefit of patients.

\section{7- Objectives:}

Objectives of this study are,

- To determine the effectiveness of physiotherapy with home based exercises in postural neck pain population of Karachi

\section{Hypothesis \\ Research Hypothesis:}

Physiotherapy with home based management is more effective than only physiotherapy in postural neck pain population of Karachi

Null Hypothesis:

There will be no difference in physiotherapy with and without home based management in postural neck pain population of Karachi

\section{Study design:}

\section{Material and methods}

\section{Non randomized controlled trial}

Setting:

The study was conducted at the Physiotherapy department of institute of orthopedic and surgery, PECHS Karachi Pakistan. Institute of orthopedic and surgery providing major concern to good quality of rehabilitative and orthopedic surgical services Patients were initially assessed by orthopedic department of the Institute and diagnosed as postural neck pain and then referred to physiotherapy department.

\section{Duration of study:}

Total duration of this study was 3 months

\section{Sample size:}

Sample size initially chosen was 50 patients which were randomly allocated to experimental group and control group. However 10 patients were unable to continue this study due to multiple reasons. Remaining 40 patients were divided into two groups; Experimental group and Control group. Experimental group comprised 20 patients and control group also comprised 20 patients.

\section{Sampling technique:}

Propulsive Sampling Sample size initially chosen randomly was 50 patients; however 10 patients were unable to participate in this study due to various reasons. Total 20 patients, who presented on Monday, Wednesday and Friday and fulfilled the inclusion criteria, were placed in the experimental group whereas 20 patients reported on Tuesday, Thursday and Saturday, were taken as a control group,

\section{Inclusion Criteria:}

Those who have following characteristics 
Effectiveness of physical therapy in postural neck pain with and without home based management.

(1) Age-above 25 and below 65 years

(2) Patients having purely postural acute, sub- acute and chronic neck pain

(3) Both male and female

\section{Exclusion Criteria:-}

Age below 25 year and more than 65 year Patients with cervical lymphadinopathy, tumor, thyroid patients, stiff TMJ, toothaches, meningitis, disc herniation, cervical Spondylosis

\section{Methodology}

Variables Home based management was independent variable whose effect was to measure on neck disability of patient with postural neck pain.

Other variable included were

1. Age,

2. Gender,

3. Occupation,

4. Neck disability.

\section{Data collection procedure}

After the selection of patients, two groups; Experimental and Controlled, having 18 patients each were subjected to pre treatment evaluation through NDI scores. Patients were then treated in the hospital with traditional therapies such as electrotherapy for 1 week on regular basis along with a home plan for experimental group while control group received no home instructions. At the day of discharge re-evaluation of the patients through NDI is documented for both groups. Patients in experimental group were instructed to follow the plan for 2 weeks and join the department for re evaluation which was again documented with NDI while control group followed no home plan and were recalled after 2 weeks. Mean for all the 3 scores were compared for each group i-e, controlled and experimental, and results were interpreted.

\section{NDI}

The NDI is a patient-completed, condition-specific functional status questionnaire with 10 items including pain, personal care, lifting, reading, headaches, concentration, work, driving, sleeping and recreation. The NDI has sufficient support and usefulness to retain its current status as the most commonly used self-report measure for neck pain. ${ }^{(19)}$ The NDI can be used to evaluate the patient's status presence and to evaluate the evolution during the therapy.

\section{NDI SCORING}

For each section the total possible score is 5: if the first statement is marked the section score $=0$, if the last statement is marked it $=5$

- If all ten sections are completed the score is calculated as follows:

Example:

16(total scored)

50 (total possible score) $\times 100=32 \%$

- If one section is missed or not applicable the score is calculated:

16 (total scored)

45 (total possible score) $\times 100=35.5 \%$

\section{Data Analysis Tools/Instruments}

Data was gathered and entered in SPSS (Statistical Package for Social Sciences). Statistical analysis was done using SPSS-14.All quantitative data has been presented in tabular form while qualitative data has been presented in graphs and pie charts etc. Independent $t$ test was used for comparative analysis.

\section{Ethical Considerations:}

- During the development of research plan I should take care about the ethical and moral values.

- My research should not cause any physical or emotional harm to the person.

- Informed consent is very necessary prior to asking question.

Day $1^{\text {st }}$ and after 2 weeks, NDI score of patients

\begin{tabular}{|c|c|c|}
\hline Patient & Day $1^{\text {st }}$ score & After 2 weeks score \\
\hline 1 & $50 \%$ & $45 \%$ \\
\hline 2 & $60 \%$ & $27.5 \%$ \\
\hline 3 & $16 \%$ & $14 \%$ \\
\hline 4 & $20 \%$ & $40 \%$ \\
\hline
\end{tabular}


Effectiveness of physical therapy in postural neck pain with and without home based management.

\begin{tabular}{|c|c|c|}
\hline 5 & $40 \%$ & $22.2 \%$ \\
\hline 6 & $48.8 \%$ & $11.11 \%$ \\
\hline 7 & $10 \%$ & $8 \%$ \\
\hline 8 & $65 \%$ & $32.5 \%$ \\
\hline 9 & $64 \%$ & $58 \%$ \\
\hline 10 & $22.2 \%$ & $0 \%$ \\
\hline 11 & $46 \%$ & $6 \%$ \\
\hline 12 & $31.1 \%$ & $20 \%$ \\
\hline 13 & $44.4 \%$ & $22.2 \%$ \\
\hline 14 & $46.6 \%$ & $15.55 \%$ \\
\hline 15 & $4 \%$ & $34 \%$ \\
\hline 16 & $22.2 \%$ & $28.8 \%$ \\
\hline 17 & $12.5 \%$ & $2.5 \%$ \\
\hline 18 & $22.2 \%$ & $60 \%$ \\
\hline 19 & $2 \%$ & $34 \%$ \\
\hline 20 & $60 \%$ & $64.4 \%$ \\
\hline 21 & $35.5 \%$ & $6.66 \%$ \\
\hline 22 & $35.5 \%$ & $35.5 \%$ \\
\hline 23 & $33.3 \%$ & $51.11 \%$ \\
\hline 24 & $4.44 \%$ & $22.2 \%$ \\
\hline 25 & $24.4 \%$ & $8.8 \%$ \\
\hline 26 & $86.6 \%$ & $53.3 \%$ \\
\hline 27 & $51.1 \%$ & $66.6 \%$ \\
\hline 28 & $60 \%$ & $53.3 \%$ \\
\hline 29 & $16 \%$ & $18 \%$ \\
\hline 30 & $33.3 \%$ & $24.4 \%$ \\
\hline 31 & $14 \%$ & $4 \%$ \\
\hline 32 & $75.5 \%$ & $57.7 \%$ \\
\hline 33 & $24.4 \%$ & $6.6 \%$ \\
\hline 34 & $52 \%$ & $45 \%$ \\
\hline 35 & $47 \%$ & $30 \%$ \\
\hline 36 & $40 \%$ & $60 \%$ \\
\hline
\end{tabular}

\section{Descriptive Analysis} Frequency Tables

Table 1

\begin{tabular}{|l|l|l|l|l|l|}
\hline \multicolumn{5}{|l|}{ Gender } & \multicolumn{5}{|c|}{} \\
\hline & & Frequency & Percent & Valid Percent & Cumulative Percent \\
\hline \multirow{3}{*}{ Valid } & Male & 14 & 38.9 & 38.9 & 38.9 \\
\cline { 2 - 6 } & Female & 22 & 61.1 & 61.1 & 100.0 \\
\cline { 2 - 6 } & Total & 36 & 100.0 & 100.0 & \\
\hline
\end{tabular}

Table 1 shows the frequency of gender in the sample.

Out of 36, there were 14 males and 22 females which constitutes $38.9 \%$ and $61.1 \%$ respectively.

Table 2

\begin{tabular}{|l|l|l|l|l|l|}
\hline Age & & Frequency & Percent & Valid Percent & Cumulative Percent \\
\hline \multirow{3}{*}{ Valid } & 21 to 30 years & 7 & 19.4 & 19.4 & 19.4 \\
\cline { 2 - 6 } & 31 to 40 years & 10 & 27.8 & 27.8 & 47.2 \\
\cline { 2 - 6 } & 41 to 50 years & 12 & 33.3 & 33.3 & 80.6 \\
\cline { 2 - 6 } & 51 to 60 years & 5 & 13.9 & 13.9 & 94.4 \\
\cline { 2 - 6 } & 61 and above & 2 & 5.6 & 5.6 & 100.0 \\
\cline { 2 - 6 } & Total & 36 & 100.0 & 100.0 & \\
\hline
\end{tabular}

Table 2 shows the frequency of age. 7 out of 36 subjects belonged to the age group 21 to 30 years. 10 people were from age group 31 to 40 years, 12 from 14 to 50 years, 5 from 51 to 60 and 2 from 61 years and above.

Table 3

\begin{tabular}{|l|l|l|l|l|l|}
\hline \multicolumn{6}{|l|}{ Occupation } \\
\hline \multirow{4}{*}{ Valid } & office workers & 12 & 33.3 & 33.3 & Cumulative Percent \\
\cline { 2 - 6 } & field worker & 5 & 13.9 & 13.9 & 33.3 \\
\cline { 2 - 6 } & house hold & 19 & 52.8 & 52.8 & 47.2 \\
\cline { 2 - 6 } & Total & 36 & 100.0 & 100.0 & \\
\hline
\end{tabular}

Table 3 shows the frequency of occupation in the sample taken. 12 participants were office workers which constitutes $33.3 \%$, 5 were field workers, constituting $13.9 \%$ and 19 were house hold workers which makes $52.8 \%$. 


\section{Cross Tabulation}

\begin{tabular}{|c|c|c|c|c|c|}
\hline \multicolumn{6}{|c|}{ gender * occupation } \\
\hline & & \multicolumn{3}{|l|}{ Occupation } & \multirow[t]{2}{*}{ Total } \\
\hline & & office workers & field worker & house hold & \\
\hline \multirow[t]{2}{*}{ gender } & Male & 7 & 5 & 2 & 14 \\
\hline & Female & 5 & 0 & 17 & 22 \\
\hline \multicolumn{2}{|l|}{ Total } & 12 & 5 & 19 & 36 \\
\hline
\end{tabular}

The table above shows the relationship between gender and occupation. Out of 14 males, 7 were office workers, 5 were field workers and 2 were experiencing house hold work. On the female's side, 5 were office workers, there was no female doing field work and 17 of them have engaged themselves in household work.

\section{Hypothesis}

\section{Research Hypothesis:}

Physiotherapy with home based management is more effective than alone physiotherapy in postural neck pain population of Karachi

\section{Null Hypothesis:}

There will be no difference in physiotherapy with and without home based management in postural neck pain population of Karachi

Test: Independent T-test

Alpha value: $95 \%$

P value: $0.05 \%$

\section{Independent T-Test}

Independent Samples Test

\begin{tabular}{|c|c|c|c|c|c|c|c|c|c|c|}
\hline & & \multicolumn{2}{|c|}{$\begin{array}{l}\text { Levene's Test for } \\
\text { Equality of Variances }\end{array}$} & \multicolumn{7}{|c|}{ t-test for Equality of Means } \\
\hline & & & & & & & & & $\begin{array}{l}95 \% \text { Con } \\
\text { Interval } \\
\text { Difference }\end{array}$ & $\begin{array}{l}\text { idence } \\
\text { f the }\end{array}$ \\
\hline & & F & Sig. & $\mathrm{T}$ & df & Sig. (2-tailed) & $\begin{array}{l}\text { Mean } \\
\text { Difference }\end{array}$ & $\begin{array}{l}\text { Std. Error } \\
\text { Difference }\end{array}$ & Lower & Upper \\
\hline $\begin{array}{l}\text { neck } \\
\text { disability }\end{array}$ & $\begin{array}{l}\text { Equal variances } \\
\text { assumed }\end{array}$ & 1.904 & .177 & -1.238 & 34 & .224 & -8.15056 & 6.58383 & -21.53050 & $\begin{array}{l}5.229 \\
39\end{array}$ \\
\hline $\begin{array}{l}\text { index } \\
\text { assessment } \\
\text { after } \quad 2 \\
\text { weeks }\end{array}$ & $\begin{array}{l}\text { Equal variances not } \\
\text { assumed }\end{array}$ & & & -1.238 & 32.792 & .225 & -8.15056 & 6.58383 & -21.54867 & $\begin{array}{l}5.247 \\
56\end{array}$ \\
\hline
\end{tabular}

$\mathrm{P}$ value is 0.025 which is lower than 0.05 so we failed to reject the research hypothesis. So it is concluded that there is significant difference in physiotherapy with and without home based exercises in postural neck pain population of Karachi

\section{Graphical Represnetation}

\section{Bar Chart}




\section{gender}

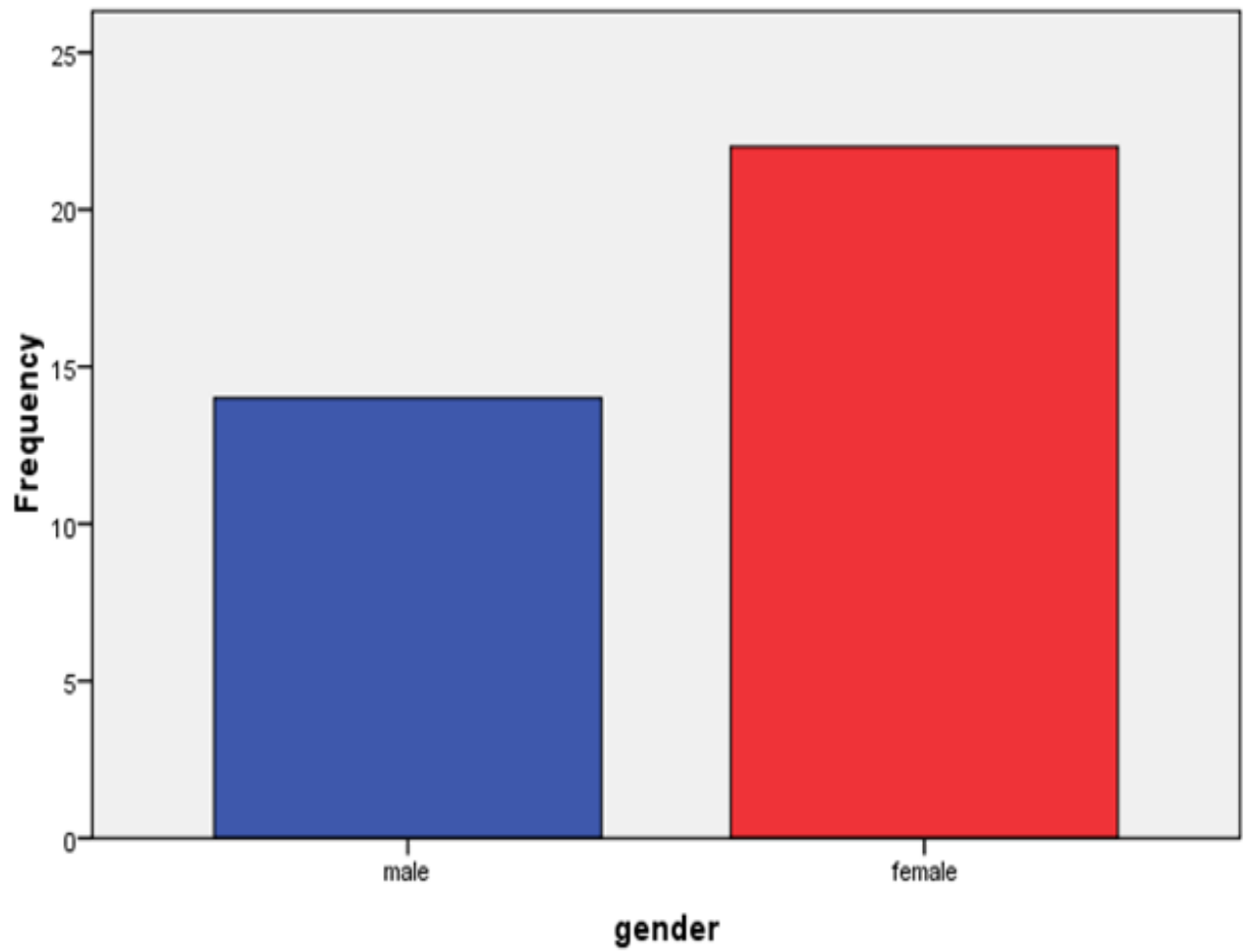

The graph above is representing frequency of male and female gender in the sample selected.

\section{Bar Chart}

\section{age}

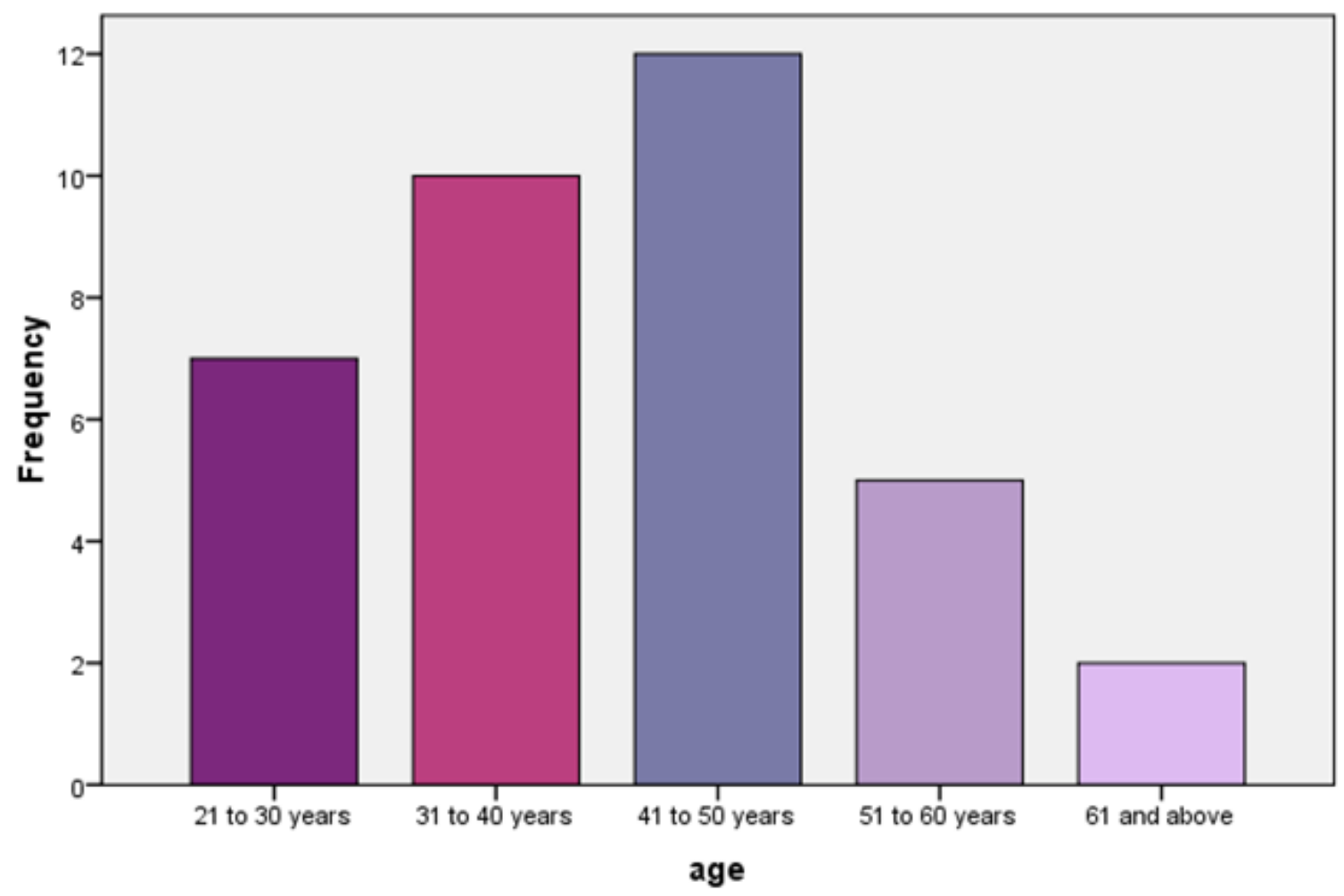

This graph is representing frequency according to age groups. 


\section{Bar Chart}

\section{occupation}

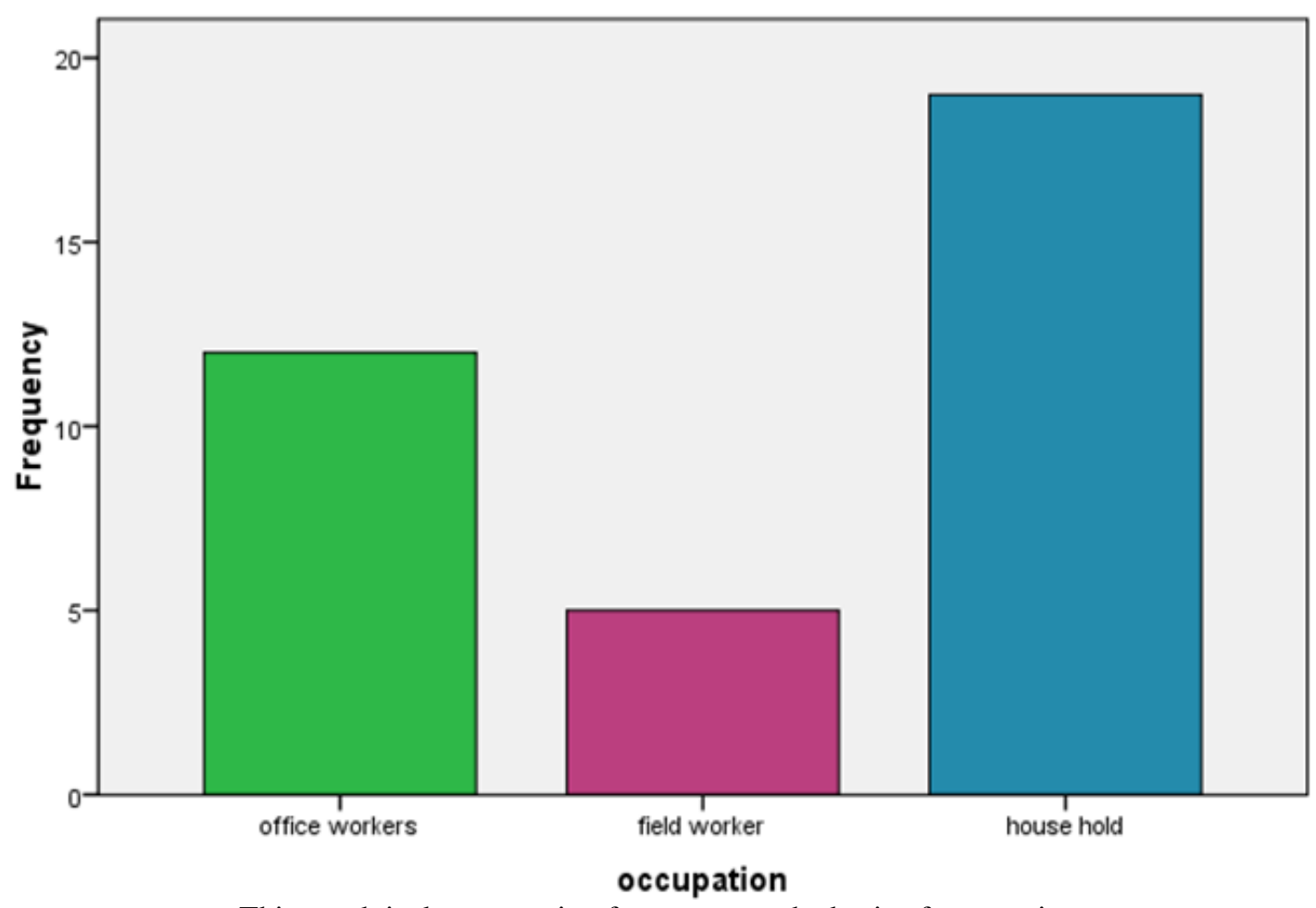

1. Pie Chart

This graph is demonstrating frequency on the basis of occupation.

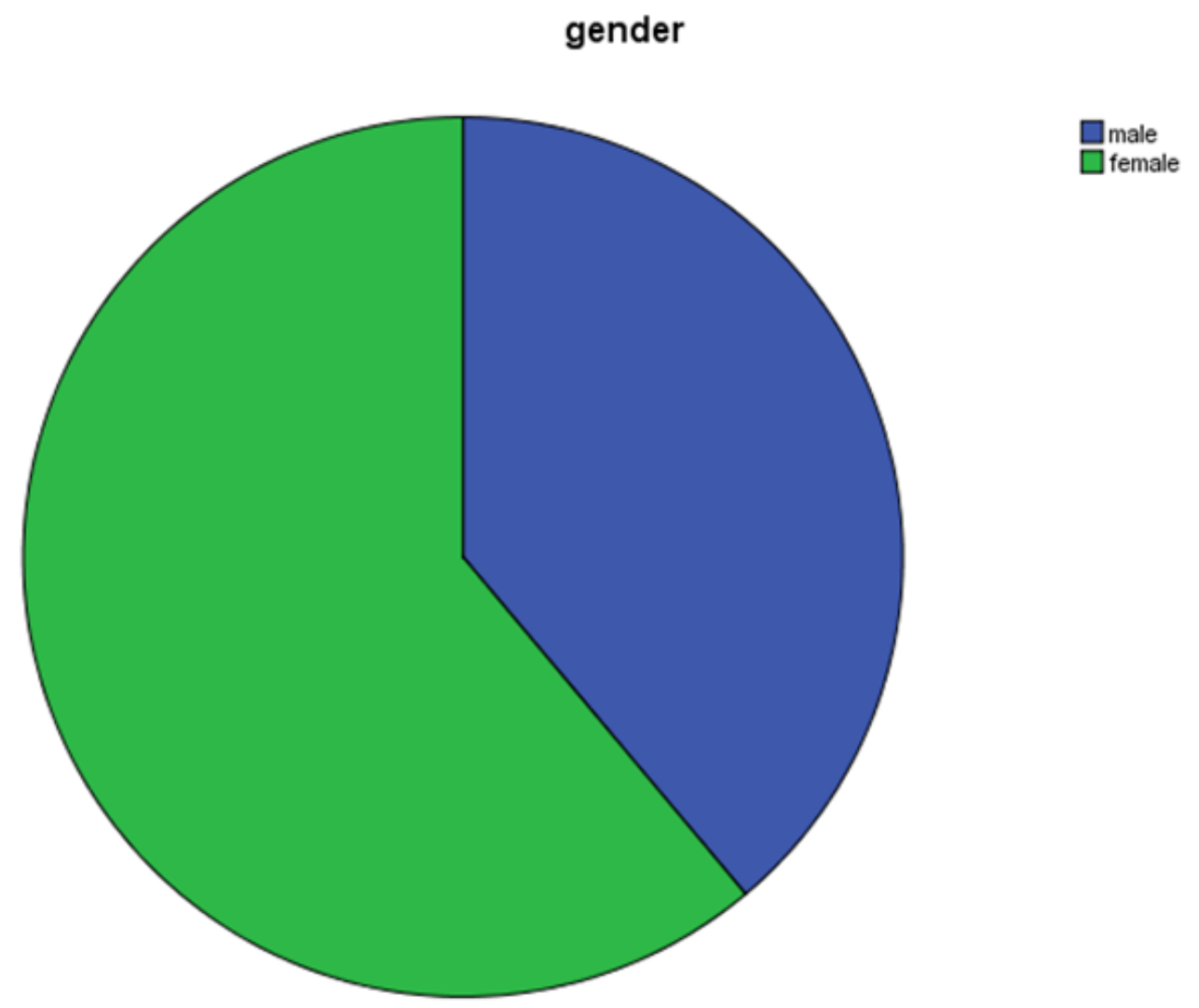

The pie chart mentioned here is demonstrating distribution according to male and female gender.

\section{Pie Chart}


age
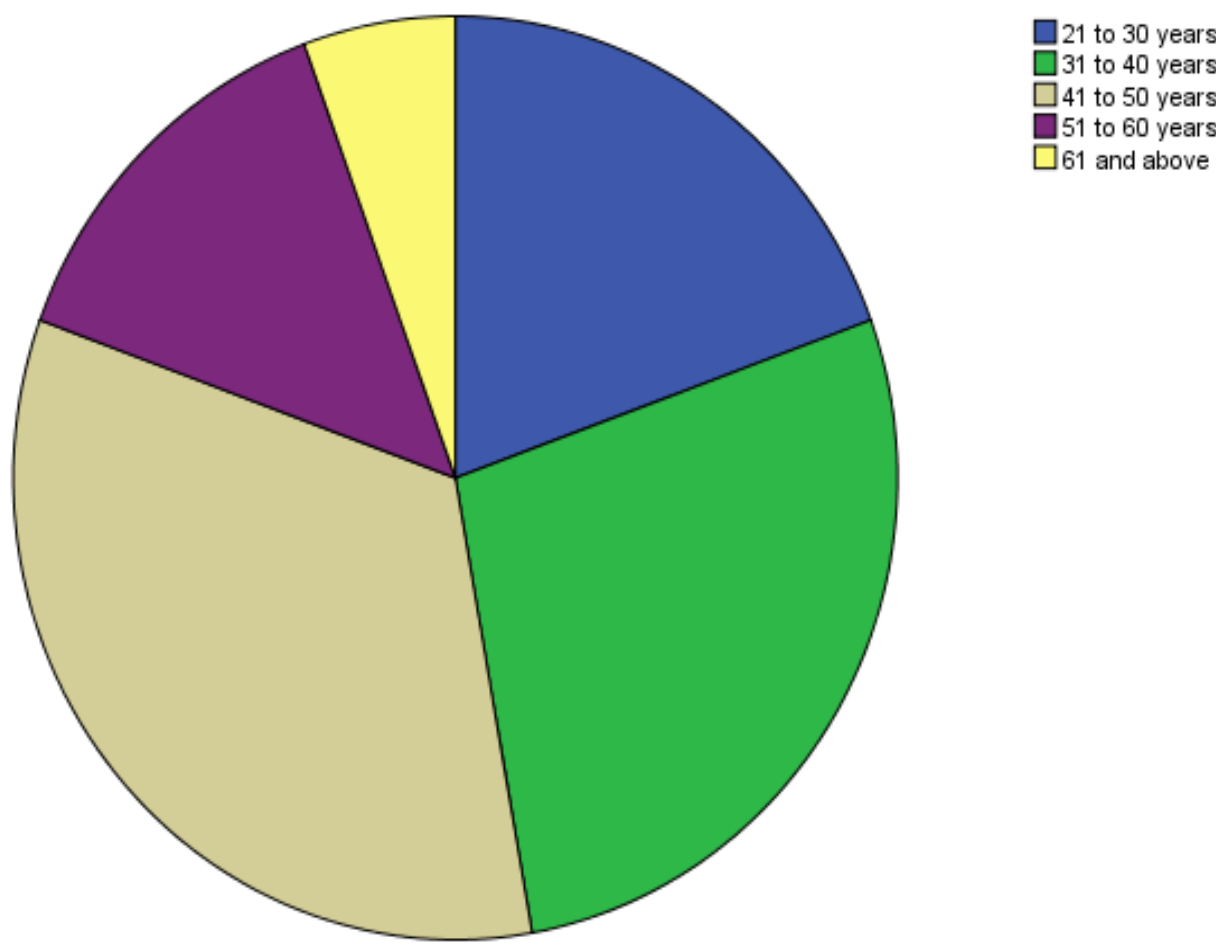

51 to 60 years

$\square 61$ and above

\section{Pie Chart}

This pie chart is representing distribution according to the age groups.

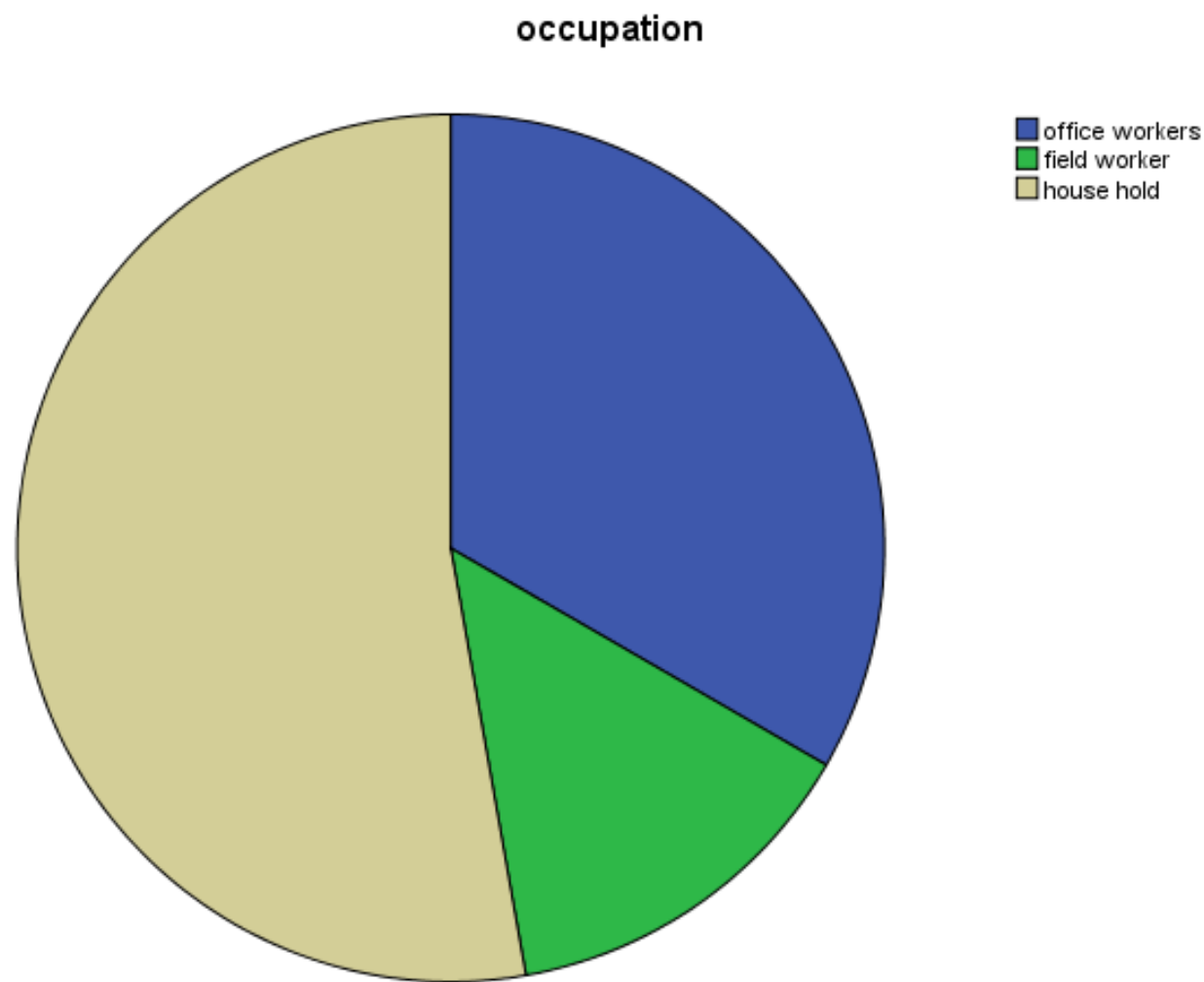

This pie chart is demonstrating distribution of sample on the basis of occupation.

\section{Results}


The results of descriptive analysis are described in the tabulated and graphical representation. The important descriptions of statistical analysis are given here for evaluation. According to the frequency of gender in the sample, out of 40, there were 15 males and 25 females which constitute $38.9 \%$ and $61.1 \%$ respectively. 8 out of 36 subjects belonged to the age group 21 to 30 years. 11 people were from age group 31 to 40 years, 14 from 14 to 50 years, 5 from 51 to 60 and 2 from 61 years and above. According to the frequency of occupation in the sample taken, 12 participants were office workers which constitutes $33.3 \%$, 5 were field workers, constituting $13.9 \%$ and 19 were house hold workers which makes 52.8\%.If we see the relationship between gender and occupation, out of 14 males, 7 were office workers, 5 were field workers and 2 were experiencing house hold work. On the female's side, 5 were office workers, there was no female doing field work and 17 of them have engaged themselves in household work. The result of independent sample t-test shows that $\mathrm{P}$ value is 0.025 which is lower than 0.05 so we failed to reject the research hypothesis. So it is concluded that there is significant difference in physiotherapy with and without home based exercises in postural neck pain.

\section{Research hypothesis analysis and results interpretation}

V. Discussion

Neck pain has been an emerging problem in the past few years due to many reasons including prolonged static posture, depression, poor sleeping and studying habits and sedentary lifestyle. This issue is neglected by the general population The purpose of this study was to examine the effect of Home based exercise on patients with postural neck pain our research hypothesis was:"Physiotherapy with home based management is more effective than alone physiotherapy in postural neck pain" Researcher wanted to observe whether there is any effect of Home based exercise on neck pain. If any effect existed, then whether it increases or decreases the neck pain. We evaluated the functional ability of patients with neck pain by using Neck Disability Index (NDI) at 1 week interval for 2 weeks. Independent t test was used for statistical analysis of the results of both groups. It was found after comparative analysis between treatment and control group that the value of $p$ was lower than 0.05. This shows that there was significant difference in the results of both groups before and after the time of study i.e. 2 weeks. Hence we may conclude that Self-management by home based exercises is effective in the management of postural neck pain. So our research hypothesis was accepted on the basis of results obtained.

During our search we find very limited studies which reported the effect of home based exercises on neck pain. This encouraged us to conduct a study measuring the effects of home based exercises on neck pain. In a study the effect of yoga was compared with home based exercise on chronic nonspecific neck pain. It was found that Yoga was more effective in relieving chronic nonspecific neck pain than a home-based exercise program. Yoga reduced neck pain intensity and disability and improved health-related quality of life. So results of this study showed that yoga was more effective than home based exercise program. ${ }^{(20)}$ In another study efficacy of a multimodal treatment emphasizing proprioceptive training (ACTIVE) with activated home exercises (HOME) and recommendation of exercise (CONTROL) in patients with nonspecific chronic neck pain was assessed. Regarding self-experienced benefit, the multimodal treatment was more efficacious than activated home exercises. ${ }^{(\mathbf{2 1})}$ In another study the effectiveness of a 12-month home-based combined strength training and stretching programme against stretching alone in the treatment of chronic neck pain was compared. No statistically significant differences in neck pain and disability were observed between the two home-based training regimens. ${ }^{(22)}$ In a study the Effect of Neck Exercise on Sitting Posture in Patients with Chronic Neck Pain was analyzed. It showed that following intervention with an exercise program targeted at training the craniocervical flexor muscles, subjects with neck pain demonstrated an improved ability to maintain a neutral cervical posture during prolonged sitting. ${ }^{(23)}$

The efficacy of a neck exercise program in patients with chronic neck pain was evaluated. Patients with chronic neck pain can benefit from the neck exercise program with significant improvement in disability, pain, and isometric neck muscle strength in different directions. ${ }^{(24)}$ It is hence worth considering if we target specific regimes towards the treatment of patients with cervical pain. More specific approach towards the treatment of pain is required for instance if patient is having pain due to cervical muscle weakness one should opt for strengthening protocol for neck rather than using electro modalities to treat the pain as it is not for long term i-e, treat the root cause. Patients who are using medications especially self-medication at home also hinder with the results and outcomes. It is therefore not clear that patients usually do not get correct medicines and make the condition worse. They should be strictly advised not to take medicines if they are getting physical therapy sessions

\section{Conclusion}

It is concluded from the results of our study that home based exercise had effect on relief of postural neck pain hence should be prescribed as a part of management of neck pain by the professionals. They should rather be recommended to follow physiotherapy treatment sessions by trained professional including manual and 
electrical modalities. It is also important to mention that we did not find any negative effect of home based exercise in our study..

\section{Limitations of the study}

- The research depends heavily on the cooperation of patients to give information.

- The sample size was limited due to difficulty in travelling to other cities.

- Also the duration of the study was limited as the thesis had to be completed and submitted within the time frame allocated by the University for the Degree Completion.

- Had there been more time the sample size could have been much larger.

- Certain amount of biasness by the patients on evaluating their level of pain after providing the treatment

- Exercises were taught to the patients of intervention group to carry out at homes. One limitation may be the skill of the patients to learn it properly and then perform it at home regularly. Because all patients belonged to different socio-economic status and with different educational background.

- Limited financial resources.

Another limitation of the study was drop out of patients. Perhaps main cause of this was transport problem. In some cases it was really difficult to keep patients motivated for long time for research activity.

\section{References}

[1]. Olaya-Contreras, P., Biopsychosocial analyses of acute and chronic pain, especially in the spine- The effect of distress on pain intensity and disability-. 20011: p. 2

[2]. Affizal Ahmad, S.T., Understanding Chronic Pain Patient's Quality of Life Using Interpretative Phenomenological Analysis Approach. Journal of Advanced Social Research, 2012. 2(2): p. 110-119.

[3]. David M. Walton, B.B., and Evelyn Etruw, Exploring the Causes of Neck Pain and Disability as Perceived by Those Who Experience the Condition: A Mixed-Methods Study. ISRN Rehabilitation, 2012. 2012: p. 7.

[4]. Neck Pain. 22 March 2013; Available from: http://www.nlm.nih.gov/medlineplus/ency/article/003025.htm

[5]. AI, B., "Cervical spondylosis and neck pain". BMJ, 2007. 334(7592): p. 527-31.

[6]. Neck Pain. 2006; Available from: http:// www. aans. org/en/ Patient\% 20 Information/ Conditions\% 20and\%20 Treatments/ Neck\%20Pain.aspx.

[7]. Neck Pain. American Academy of Orthopaedic Surgeon November 2009; Available from: http:// orthoinfo .aaos.org /topic. cfm?topic $=\mathrm{a} 00231$

[8]. Neck. 23 June 2013; Available from: http://en.wikipedia.org/wiki/Neck.

[9]. Robert E Windsor, M., FAAPMR, FAAEM, FAAPM. Medscape.

[10]. Schafer, D., PhD, The cervical spine. Clinical Biomechanics: Musculoskeletal Actions and Reactions. Vol. 2.

[11]. Erik E Swartz, R.T.F., $\dagger$ and Mike Cendoma $\ddagger$, Cervical Spine Functional Anatomy and the Biomechanics of Injury Due to Compressive Loading. Athl Train, 2005. 40(3): p. 155-61.

[12]. Dr. Edward Crowther, D.R.G., Dr. Gary Lee and Dr. Moez Rajwani, The Bone and Joint Decade Task Force on Neck Pain. The Institute for Work \& Health (IWH), 2010. 33(4).

[13]. in neck pain: The Ohio State University Wexner Medical Center -

[14]. Overview of Neck Pain. AAPM\&R; Available from: http://www.aapmr.org/patients/conditions/msk/spine/pages/overview-of-neckpain.aspx.

[15]. staff, m.c. Neck pain.

[16]. staff, M.c. Herniated disk.

[17]. Kenny, D.T., Non-specific Neck Pain. 2010. 39.

[18]. Acute and Chronic Neck Pain.

[19]. Melinda Ratini, D., MS, Pain Management: Neck and Shoulder Pain. WebMD Health News:, 2013.

[20]. Dr John Pillinger, G., Neck pain.

[21]. Silva, A.G., Punt, T.D., Sharples, P., Vilas-Boas, J.P., \& Johnson, M.I, Head posture and neck pain of chronic nontraumatic origin: A comparison between patients and pain-free persons. Archive Physical Medicine Rehabilitation., 2009. 90: p. 669-674.

[22]. What treatments are there for neck problems?.03-07-2013]; Available from: http://www.arthritisresearchuk.org/arthritisinformation/conditions/neck-pain/treatments.aspx.

[23]. staff, M.c. Neck pain. Mayo clinic Sept. 11, 2012

[24]. 03-07-2013]; Available from: http://www.mayoclinic.com/health/neck-pain/DS00542/DSECTION=lifestyle-and-home-remedies.

[25]. Cervical Disc Disease Treatment: Managing Neck Pain at Home.Available from: http://www.webmd.com/painmanagement/managing-neck-pain-home.

[26]. Neck Pain- Home Treatment.

[27]. Macdermid JC, W.D., Avery S, Blanchard A, Etruw E, McAlpine C, Goldsmith CH, Measurement properties of the neck disability index a sustematic review Journal of Orthopedic and Sports Physical Therapy. 39(5): p. 400-17.

[28]. Cramer, H.M.L., Romy PhD*; Hohmann, Claudia MD*; Lüdtke, Rainer MSc†; Haller, Heidemarie MSc*; Michalsen, Andreas MD $\$$; Langhorst, Jost MD*; Dobos, Gustav MD, Randomized-controlled Trial Comparing Yoga and Home-based Exercise for Chronic Neck Pain. Clinical Journal of Pain:, 2013. 29(3): p. 216-223.

[29]. Taimela, S.M., DMSc*†; Takala, Esa-Pekka MD, DMScł; Asklöf, Tom MD*; Seppälä, Kitty PT*; Parviainen, Sirkka RN*, Active Treatment of Chronic Neck Pain: A Prospective Randomized Intervention. Spine, 2000. 25(8): p. 1021-1027.

[30]. Häkkinen A, K.H., Hannonen P, Ylinen J., Strength training and stretching versus stretching only in the treatment of patients with chronic neck pain: a randomized one-year follow-up study. Clinical Rehablitation, 2008. 22(7): p. 592-600.

[31]. Falla D, J.G., Russell T, Vicenzino B, Hodges P., Effect of neck exercise on sitting posture in patients with chronic neck pain. Physical Therapy, 2007. 87(4): p. 408-417.

[32]. Chiu TT, L.T., Hedley AJ., A randomized controlled trial on the efficacy of exercise for patients with chronic neck pain. Spine, 2005. 30(1): p. 1-7. 
Effectiveness of physical therapy in postural neck pain with and without home based management.

[33]. Journal of Manipulative and Physiological Therapeutics - July 2004 (Vol. 27, Issue 6, Pages 414-420, DOI: 10.1016/j.jmpt.2004.05.007) 